\title{
Cortically Evoked Motor Responses in Patients with Xp22.3-Linked Kallmann's Syndrome and in Female Gene Carriers
}

\author{
Adrian Danek, MD, ${ }^{*} \dagger$ Babett Heye, MD $\$$ and Robert Schroedter, BSc*
}

\begin{abstract}
Patients with Kallmann's syndrome show hypothalamic hypogonadism, hyposmia, and congenital mirror movements. As a correlate, a defect of gonadotropic neuron migration into the brain was recently detected. Considering abnormal outgrowth of neurons also as a possible substrate underlying mirror movements, we studied 3 patients and 2 asymptom-

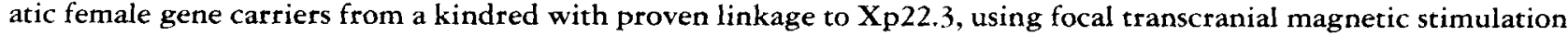
of motor cortex hand areas with a figure-eight coil. In all 3 affected brothers, bilateral responses could be evoked almost simultaneously in their thenar muscles (slight latency differences were statistically insignificant). In contrast, the mother and the maternal aunt showed only unilateral, normal thenar responses, even with maximum tolerable stimulator output and high signal amplification. Correspondingly, mirror movements were present in the patients, but not in the gene carriers. Bilaterality of cortically evoked hand muscie responses and mirror movements, therefore, behaved as X-chromosomal recessive traits. A likely cause might be a disorder of neuronal outgrowth in the motor system, particularly of inhibitory callosal fibers. For normal anatomical development of the motor system, one intact Xp22.3 gene seems necessary.
\end{abstract}

Danek A, Heye B, Schroedter R. Cortically evoked motor responses in patients with Xp22.3-linked Kallmann's syndrome and in female gene carriers. Ann Neurol 1992;31:299-304

Kallmann's syndrome is defined by inherited hypogonadotropic hypogonadism with anosmia or hyposmia due to agenesis of the olfactory bulbs and tracts $[1-3]$. Patients often also show synkinesia, that is, congenital mirror movements [4]. The mode of transmission of Kallmann's syndrome varies in different families [5], but its $\mathrm{X}$-linked form has been definitely assigned to $\mathrm{Xp} 22.3[6]$

Congenital mirror movements in Kallmann's syndrome, like those in the Klippel-Feil syndrome of cervical spine and cord malformation [7] and those found as an isolated, probably autosomal dominant trait [8], still lack a generally accepted explanation as to their anatomical and physiological basis [9]. In the latter forms of congenital mirror movements, an electrophysiological correlate seem to be bilateral cortically evoked motor responses (CEMRs) in the distal musculature [10-15]. In contrast, normal control subjects show only unilateral responses, contralateral to the hemisphere stimulated $[15,16]$. Abnormal arrangement of the central motor system with bilaterally descending pathways is therefore discussed as underlying congenital mirror movements.

$\mathrm{X}$-linked Kallmann's syndrome thus seems an ex- cellent model to investigate congenital mirror movements, since at least one of its features, hypogonadotropic hypogonadism, can be explained by defective neuronal migration [17]. Studies on stimulation of motor cortex in patients with Kallmann's syndrome have not yet been reported. The intriguing question is how the Kallmann gene affects the development, anatomy, and function of motor pathways. We therefore studied members from a kindred with proven linkage to

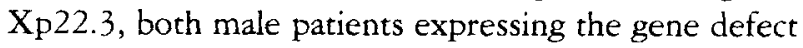
and asymptomatic female gene carriers, using focal transcranial magnetic stimulation of the motor cortex with a figure-eight coil $[15,16]$.

\section{Subjects and Methods}

Five members from a family with Kallmann's syndrome and proven linkage to $\mathrm{Xp} 22.3$ [6] were recruited as subjects for this study (Fig 1). Written informed consent was obtained. The 3 brothers, M. K., O. K., and J. K. (01 III 4-6 of [6]), 17, 16, and 14 years old, showed hypogonadotropic hypogonadism, hyposmia, and mirror movements. Mirror movements were present in the upper limbs, most pronounced in the distal musculature. Distally, movements of single or several fingers were accompanied by unsuppressible, symmetrical movements in the opposite fingers on
From the *Neurologische Klinik, Klinikum Grosshadern, institut für Medizinische Psychologie, and + Abteilung für Pädiatrische Genetik der Kinderpoliklinik, Ludwig-Maximilians-Universität, München, Germany.
Received Jun 18, 1991, and in revised form Aug 9. Accepted for publication Aug 11, 1991.

Address correspondence to Dr Danek, Neurologische Klinik, Postfach 701260, D 8000 München 70, Germany. 


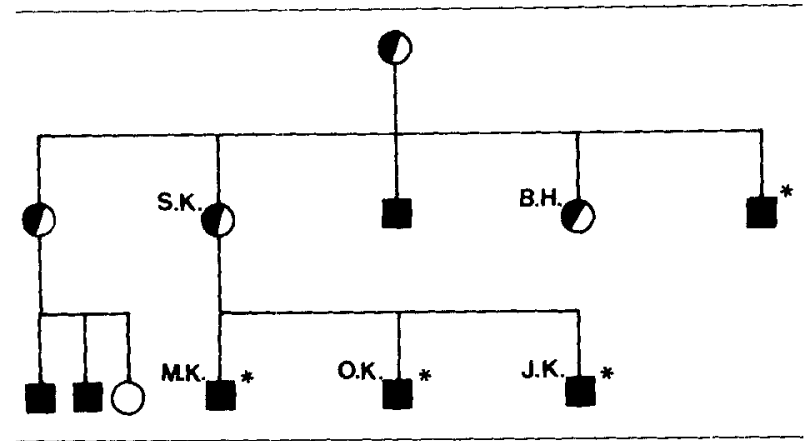

Fig 1. Pedigree of family with Xp22.3-linked Kallmanr's syndrome. All males uere affected (black squares) and mirror morements (asterisks) uere documented in the majority. Four femaler were Kallmann gene carriers (half-filled circles), as evident from manifestation of the syndrome in their sons and/or DNA analysis $16 \%$.

Hexion, extension, abduction, and adduction. Mirror activity was also present for flexion-extension and pronationsupination of the wrist. More proximally, elbow flexionextension and shoulder abduction evoked mirror activity only in 1 brother $(\mathrm{J} . \mathrm{K}$.) when movements were performed against resistance.

In addition, l patient (M. K.) showed a severe limitation of left eye upgaze with abduction during the attempt and double vision on right, middle, and left upward gaze. The findings seem compatible with Brown's syndrome of the superior oblique tendon sheath, yet a central origin does not seem excluded since this same patient lacked convergence, too. Visual acuity was normal in both eyes, as were horizontal saccadic and pursuit movements. One brother (J. K.) showed associated movements also of the jaw (lateral deviation) on gaze to the extreme right or left. He needed special schooling because of developmental dyslexia.

Neurological findings otherwise were normal in the 3 brothers. Particularly, there were no mirror movements during movements of the lower limbs, no reflex anomalies, no pyramidal tract signs, and no extinction on double simultaneous sensory stimulation. All brothers were righthanded, $100 \%$ according to the item list of Salmaso and Longoni [18].

The 2 sisters, S. K. and B. H. (01 II 7 and 9 of [6]), carry one gene each with the Kallmann defect, on the $\mathrm{X}$ chromosome inherited from their mother, as shown for both by DNA analysis and for S. K. by clinical manifestation of the syndrome in her sons. Both were normal neurologically and did not show mirror movements.

Surface electromyographic (EMG) responses were recorded from both thenars (abductor pollicis brevis muscle) by tinplate surface electrodes (13K60 Dantec, Skovlunde, Denmark) over the muscle belly and the distal tendon, respectively. Signals were amplified, filtered with a band pass of $2 \mathrm{~Hz}$ to $10 \mathrm{kHz}$, and analyzed using a multichannel recorder with data storage and processing modules (Neuropack 4 mini, Nihon Kohden Deutschland, Bad Homburg, Germany).

To control for recording conditions and to determine the maximum peripheral thenar response ( $M$ response), the me- dian nerve was stimulated with a bipolar stimulating electrode at the wrist. Stimulus strength was increased successively and the response amplitude at plateau determined.

For documentation of involuntary mirrored activity, the subjects were verbally instructed to abduct their thumbs against resistance or to relax them during 5 -second intervals of simultaneous bilateral monitoring of thenar surface EMG activity.

CEMRs were elicited by focal transcranial magnetic cortical stimulation with a figure-eight coil. We used a commercially available stimulation system (Magstim $200 \mathrm{HP}$, Novametrix Medical Systems, Wallingford, CT) with a peak magnetic field of 2.5 tesla. The coil consisted of two rings of 10 turns of copper wire, each with an inner diameter of 5.5 $\mathrm{cm}$ and an outer diameter of $9 \mathrm{~cm}[\mathrm{I} 6]$. The recording period was from $10 \mathrm{msec}$ before to $90 \mathrm{msec}$ after stimulation.

The coil was positioned with its handle in the sagittal ditcction and pointing posteriorly. The center of the coil, that is, the point where the circumferences of both rings meet, was placed on the scalp at a point $5 \mathrm{~cm}$ to the right or to the left of $\mathrm{Cz}$, as defined according to the International 10-20 System. This site corresponds to the motor cortex hand area: Optimal hand muscle responses are obtained from this point. Before the stimuli were applied, the subjects were asked to completely relax their hands and to facilitate CEMRs by holding their feet extended, with an angle of approximately 90 degrees at the ankle. This is the routine facilitation procedure for hand muscle responses in our laboratory [11, 19, 20$].$

First, thresholds for eliciting EMG responses in the thenar muscles were determined by increasing the strength of stimulation in steps of $10 \%$ of maximum stimulator output. For quantitation, three successive responses were elicited by suprathreshold stimulation. Onset latency of responses was. measured on the screen with the help of cursors, positioned. where a deviation from baseline could first be detected. Amplitudes were determined automatically after the two most extreme peaks of the CEMR had been marked manually with the screen cursors. Minimum temporal resolution was 0.2 msec.

\section{Results}

In all 3 patients with Kallmann's syndrome, surface EMG activity could be documented contralaterally during voluntary movement of either thumb, whereas no mirrored activity was detected in the 2 carriers. Onset of voluntary and mirrored movement in the patients seemed simultaneous, yet further analysis of possible latency differences beyond the minimum temporal resolution of the recording condition $(20 \mathrm{msec})$ was not performed.

Threshold to obtain CEMRs in the thenar muscles on stimulation of the motor cortex hand area was $60 \%$ of maximum stimulator output in 1 brother (J. K.) and $40 \%$ in the remaining subjects. The stimulation effect was lateralized, since hand motor responses were not observed when the stimulating coil was positioned over the vertex or otner midline points of the skull. In the latter condition, movements were only observed in the lower extremities. 


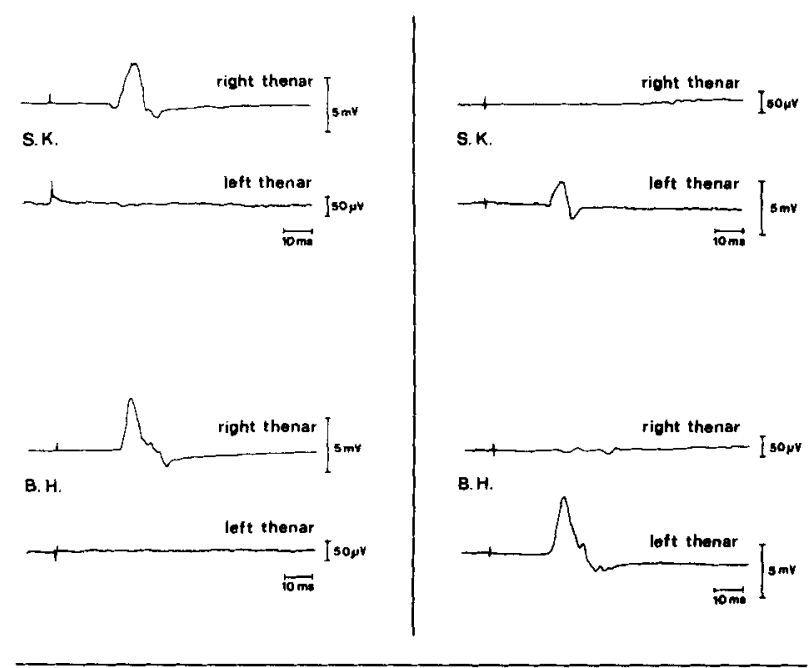

Fig 2. Focal transcranial magnetic stimulation of the motor cortex band area with a figure-eight coil (over $C_{3}$, traces on the left, and $C_{4}$, traces on the right) in the 2 female Kallmann gene carriers without mirror movements ( $S . K$, upper traces; $B$. H., lower traces), at maximum tolerable stimulator output (100\% in S. K., 80\% in B.H.). Both bad strictly unilateral electromyograpbic responses in the thenar muscles opposite to the side of cortical stimulation. This is also the result found in normal control subjects. (The slight right thenar activity in $B . H$. on stimulation of ipsilateral cortex, lower right traces, was not observed in five furtber trials and therefore corresponds to noise.)

Thenar responses in both female carriers occurred only unilaterally, on the side contralateral to the hemisphere stimulated. This is a typical result for normal subjects [16]. CEMRs in the ipsilateral thenar muscles were not detected even with stimulation at maximum tolerable stimulator output $(80-100 \%)$ and the highest recording sensitivity possible (Fig 2 ).

In contrast to this normal result, all 3 patients with Kallmann's syndrome showed thenar responses bilaterally already at threshold stimulation. Increasing the strength of the stimulus left this pattern of evoked responses unchanged (Fig 3). Interestingly, in the majority of stimulations, the amplitudes of the "normal" CEMRs, contralateral to the side of cortical stimulation, were smaller than those of the simultaneous ipsilateral responses (Table 1). In 2 of the brothers, they ranged from as little as $17 \%$ to about the same size $(80 \%)$ as those elicited ipsilaterally (see Table 1). Only in 1 of the brothers (O.K.) were most contralateral CEMRs larger, but still two out of six response pairs

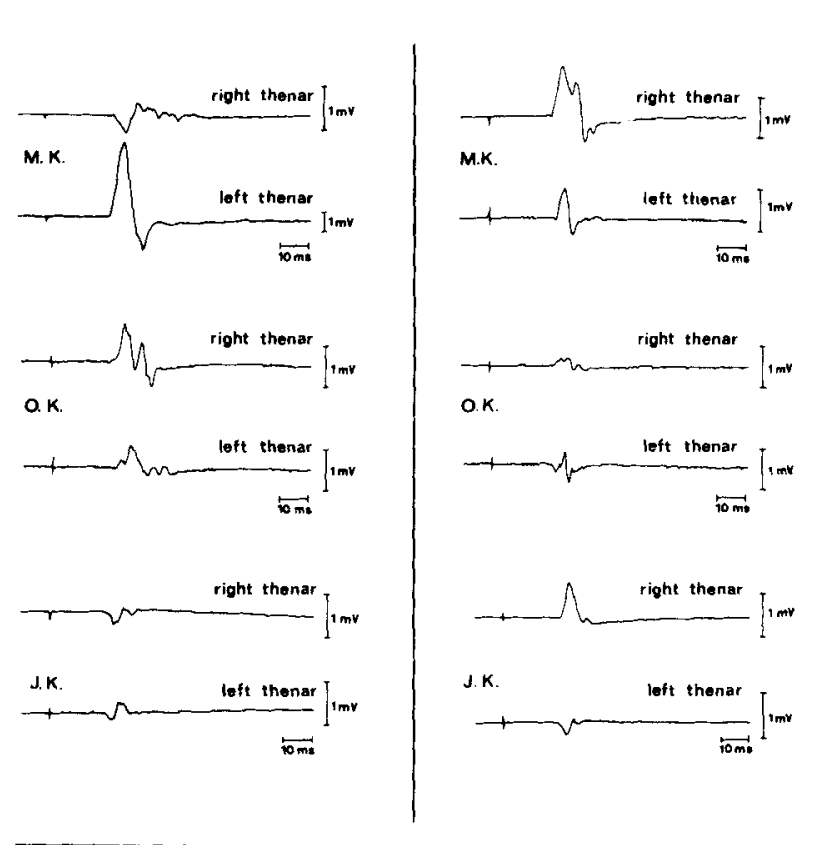

Fig 3. Three patients with X-linked Kallmann's syndrome and mirror movements ( $M$. $K$., top traces; $O . K$., middle traces; and J. K., bottom traces) showed cortically evoked motor responses simultaneously in both thenar muscles, irrespective of which hemisphere bad been subjected to focal transcranial mag. netic stimulation. The relative size of ipsilateral versus contralateral evoked amplitudes varied between subjects, yet ipsilateral responses tended to be larger. The results shown were obtained with supratbreshold, submaximal stimulation $160 \%$ stimulator output in M. K., 80\% in O.K. and J. K.).

Table 1. Cortically Evoked Thenar Responses in Three Brotbers with Kallmann's Syndrome ${ }^{\mathrm{a}}$

\begin{tabular}{lllll} 
& Side of & \multicolumn{2}{c}{ Amplitude $(\mathrm{mV})$} & \\
\cline { 3 - 4 } Subject & Stimulation & Contralateral & Ipsilateral & Ratio \\
\hline M. K. & R & $0.9-1.1$ & $1.2-2.5$ & \\
& L & $0.4-0.5$ & $0.2-3.3$ & \\
& & & & $0.17-0.73$ \\
O. K. & R & $0.2-0.6$ & $0.2-0.3$ & \\
& L & $0.8-1.3$ & $0.3-0.6$ & \\
& & & & $0.75-3.75$ \\
J. K. & R & $0.2-0.4$ & $0.7-1.0$ & \\
& L & $0.3-0.4$ & $0.3-0.4$ & \\
& & & & $0.38-0.80$
\end{tabular}

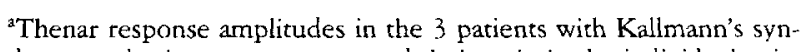
drome and mirror movements and their ratio in the individual pairs of responses (contralateral vs ipsilateral, values corrected for peripheral $M$ responses) are shown. All stimulations were performed in triplicate, $20 \%$ above threshold. 
showed them to be equal or smaller, compared to the ipsilateral ones.

The range of latencies of all contralateral, "normal" thenar responses at suprathreshold stimulation in all 5 subjects was 18.0 to 23.2 msec. Mean values ( \pm : standard deviation) for thenar CEMRs in the side contralateral to stimulation were $20.8 \pm 0.8 \mathrm{msec}$ in the female gene carriers and $20.2 \pm 1.7 \mathrm{msec}$ in the patients. There was no significant difference between the values for patients and those for gene carriers ( $t$ test, $p>$ 0.2 ). Also, the values are not pathological, compared to those of normal control subjects. In these, on magnetic cortical stimulation with a large circular coil (mean diameter, $90 \mathrm{~mm}$ ) our laboratory established a mean CEMR value of $21.9 \mathrm{msec}$ for the right and $22.1 \mathrm{msec}$ for the left thenar ( $1.7 \mathrm{msec}$ standard deviation). For the type of figure-eight coil used here, in normal subjects latencies to the hypothenar of up to $25.5 \mathrm{msec}$ can be found with nonspecific facilitation [16].

The ipsilateral CEMR latency of the patients was $20.1 \pm 1.3 \mathrm{msec}$, which is not significantly different from their contralateral CEMRs (paired $t$ test, $p>0.8$ ). On comparison of the response pairs of the individual patients, only in $1(\mathrm{O} . \mathrm{K}$.) did the contralateral responses generally occur earlier, whereas this relationship was reversed in all of the oldest brother's (M. K.) and most of the youngest brother's (J.K.) responses (Table 2). A slight tendency for the ipsilateral responses to be faster may be reflected in the sum value of latency differences between all single pairs of re-

Table 2. Latency of Cortically Evoked Thenar Responses ${ }^{\text {a }}$

\begin{tabular}{|c|c|c|c|c|}
\hline \multirow[b]{2}{*}{ Subject } & \multirow{2}{*}{$\begin{array}{l}\text { Side of } \\
\text { Stimulation }\end{array}$} & \multicolumn{2}{|c|}{ Latency (msec) } & \multirow[b]{2}{*}{ Difference } \\
\hline & & Contralateral & Ipsilateral & \\
\hline \multicolumn{5}{|l|}{ Kallmann patients } \\
\hline \multirow[t]{6}{*}{ M. K. } & $\mathrm{R}$ & 22.6 & 22.0 & +0.6 \\
\hline & & 23.2 & 21.6 & +1.6 \\
\hline & & 22.8 & 21.6 & +1.2 \\
\hline & $\mathrm{L}$ & 22.2 & 21.0 & +1.2 \\
\hline & & 21.8 & 21.0 & +0.8 \\
\hline & & 21.8 & 21.0 & +0.8 \\
\hline \multirow[t]{6}{*}{ O. K. } & $\mathrm{R}$ & 19.2 & 20.8 & -1.6 \\
\hline & & 18.0 & 21.6 & -3.6 \\
\hline & & 19.8 & 20.4 & -0.6 \\
\hline & $\mathrm{L}$ & 20.0 & 20.0 & \pm 0.0 \\
\hline & & 19.8 & 20.0 & -0.2 \\
\hline & & 20.0 & 20.2 & -0.2 \\
\hline \multirow[t]{6}{*}{ J. K. } & $\mathrm{R}$ & 18.6 & 19.0 & -0.4 \\
\hline & & 18.2 & 17.8 & +0.4 \\
\hline & & 18.2 & 19.4 & -1.2 \\
\hline & $\mathrm{L}$ & 19.0 & 18.4 & +0.6 \\
\hline & & 19.2 & 18.4 & +0.8 \\
\hline & & 19.0 & 18.4 & +0.0 \\
\hline Mean $( \pm S D)$ & & $20.2 \pm 1.7$ & $20.1 \pm 1.3$ & \\
\hline Range & & $18.0-23.2$ & $17.8-22.0$ & $-3.61+1.6$ \\
\hline \multicolumn{5}{|c|}{ Kallmann gene carriers } \\
\hline \multirow[t]{6}{*}{ S. K. } & $\mathrm{R}$ & 20.0 & - & \\
\hline & & 20.0 & - & \\
\hline & & 20.6 & 一 & \\
\hline & $\mathrm{L}$ & 21.0 & - & \\
\hline & & 20.0 & - & \\
\hline & & 19.8 & - & \\
\hline \multirow[t]{6}{*}{ B. $\mathrm{H}$. } & $\mathrm{R}$ & 20.4 & - & \\
\hline & & 21.6 & - & \\
\hline & & 21.4 & - & \\
\hline & $\mathrm{L}$ & 21.6 & - & \\
\hline & & 21.4 & - & \\
\hline & & 22.0 & - & \\
\hline Mean $( \pm S D)$ & & $20.8 \pm 0.8$ & & \\
\hline Range & & $19.8 \pm 22.0$ & & \\
\hline
\end{tabular}

${ }^{a}$ Latency of thenar responses on suprathreshold stimulation (threshold plus $20 \%$ of maximum stimulator output) in 3 patients with $X$-linked Kallmann's syndrome and mirror movements and in 2 unaffected Kallmann gene cartiers (values in milliseconcls). For the paticnts, the temperal difference between the bilateral responses (contralateral minus ipsilateral) is also shown. 
sponses, yet there is no clear-cut temporal advantage for either the ipsilaterally or the contralaterally projecting pathways in Kallmann's syndrome.

\section{Discussion}

This study is the first to investigate CEMRs in subjects with Kallmann's syndrome and mirror movements. The results show that both mirror movements and bilaterality of evoked motor responses in this family behave as $\mathrm{X}$-chromosomal recessive traits as do hypogonadotropic hypogonadism and hyposmia.

The latter two features of X-linked Kallmann's syndrome can be related to the recent finding of arrest of migration of gonadotropic cells in an affected fetus [17]. It is well established in experimental animals that gonadotropic cells positive for luteinizing hormonereleasing hormone (LHRH) migrate from the medial olfactory placode along the terminalis nerve into the cranial cavity, where they traverse the basal meningeal coverings in order to enter the brain and finally reach the hypothalamus [21]. Analogous findings have been made in normal human fetuses. In contrast, the Kallmann fetus showed numerous LHRH-positive cells clustered below the basal meninges, obviously unable to complete their migration [17].

Olfactory receptor cells seem affected by such arrest of migration, too. The sites through which their centrally projecting axons enter the cranium (i.e., the perforations of the cribriform plate) are reduced in number in Kallmann's syndrome [3]. Weidenreich, in 1914 , had suggested arrested olfactory fila migration and subsequent olfactory bulb regression as underlying the Kallmann brain malformation [3]. Interestingly, defective neuronal migration in language-related cortex is discussed as a possible basis of developmental dyslexia [22], which exists in one of our patients.

The basic defect in Kallmann's syndrome then seems to be the inability of particular neurons and axons to reach their target sites. LHRH-positive neurons do migrate up to the meninges and some olfactory nerves and cribriform plate perforations are present, showing that the presumed disorder of neuronal migration cannot be a general one. It rather is a failure of axons to cross a barrier like the meninges, probably caused by lack of a specific facilitating factor. A multitude of "axonal growth-associated proteins" and "adhesion molecules" have been described $[23,24]$ and the Xp22.3 gene product might be such a factor (see Addendum).

It is tempting to speculate that defective axonal growth in the developing motor system causes both mirror movements and bilaterality of CEMRs. EMG studies in 2 brothers with Kallmann's syndrome demonstrated that voluntary and mirrored activities differ in onset by less than $20 \mathrm{msec}$ [25], a result supported by our own preliminary observations of surface EMG activity during verbally elicited thumb abduction. In- terpretations of such short latencies in congenital mirror movements imply a common motor signal to motor neurons on both sides of the spinal cord $[25,26]$. The almost simultaneous occurrence of motor responses in hand muscles bilaterally on focal transcranial cortical stimulation in several subjects without Kallmann's syndrome but with congenital mirror movements [10-15] and in our patients with Kallmann's syndrome is compatible with this assumption. Concerning the anatomy of the motor command pathway in congenital mirror movements, results of long-latency reflex and motor unit correlogram studies with crossed responses in homologous contralateral hand muscles even argue for a connection of single cortical motor neurons with the motor neuron pool on both sides of the spinal cord by axon bifurcations $[14,15,27]$.

Yet, bilateral distribution of descending motor pathways cannot sufficiently explain mirror movements. In normal monkeys, some neurons in the primary motor cortex address hand muscles bilaterally [28]. Also in normal humans, corticospinal connections are bilaterally organized, at least for the lower extremities, since hemisections of the spinal cord only temporarily cause leg paresis [29]. In the upper extremities, acquired mirror movements along with bilaterality of CEMRs in patients who have had hemispheric damage suggest disinhibition of such motor pathways [19, 30].

Accepting latent bilaterality of motor commands and motor responses as normal, an alternative "inhibition theory" of mirror movements postulates that commands from the motor cortex that would excite ipsilateral muscles via ipsilateral pathways normally are suppressed by the opposite, not primarily active, motor cortex [31]. Such inhibition necessary for normal unilateral, unmirrored movement is thought to be exerted via cortico-cortical fibers traveling through the corpus callosum [31]. Correspondingly, congenital mirror movements have been observed in agenesis of the corpus callosum $[9,32]$. The postulated callosal fiber system might tonically inhibit ipsilaterally directed commands already within the motor cortex.

A study of movement-related cortical potentials in a patient with Kallmann's syndrome and mirror movements supports the "inhibition theory" [33]. When he moved the index finger of one hand, the late negative slope was present bilaterally, in contrast to its unilateral appearance in normal subjects. A recent positron emission tomography study gave an analogous result, with bilateral motor cortex activity accompanying intended unilateral hand movement in a patient with isolated congenital mirror movements [10]. If cortical motor axon bifurcations were the sole correlates of mirror movements, the activation in these paradigms ought to be confined to one hemisphere.

In summary, these findings raise the question of whether the absence of a Xp22.3 gene product in $\mathrm{X}$ - 
linked Kallmann's syndrome leads to an arrest of the migration of callosal fibers necessary for interhemispheric motor inhibition, though the majority of fibers and the gross anatomy of the corpus callosum appear normal $[3,34]$. However, it seems clear, as evident from the female carriers without mirror movements and with normal motor evoked responses, that the gene dose of a single intact Xp22.3 locus is sufficient for normal wiring of motor connections.

\section{Addendum}

The postulate of homology between the Xp22.3 Kallmann gene product and cell adhesion molecules has recently been proved in two different laboratories. See Nature 1991;353:529-536 and Cell 1991;67:423-435.

This study was supported by grants from Friedrich-Baur-Stiftung, Wilhelm-Sander-Stiftung and Deutsche Forschungsgemeinschaft ( $\mathrm{Po}$ 122/11-1).

We thank Profs Th. Brandt and W. Fries for discussion, and acknowledge the contributions of Drs Th. Meitinger, M. Dieterich, Th. N. Witt, and W. Paulus.

\section{References}

1. Kallmann FJ, Schoenfeld WA, Berrera SE. The genetic aspects of primary eunochoidism. Am J Ment Defic 1944,48:203-236

2. Lieblich JM, Rogol AD, White BJ, Rosen SW. Syndrome of anosmia and hypogonadotropic hypogonadism (Kallmann syndrome). Am J Med 1982;73:506-519

3. Weidenreich F. Über partiellen Riechlappendefekt und Eunuchoidismus beim Menschen. Z Morphol Anthropol 1914;18: $157-190$

4. Schwankhaus JD, Currie J, Jaffe MJ, et al. Neurologic findings in men with isolated hypogonadotropic hypogonadism. Neurology 1989; 39:223-226

5. White BJ, Rogol AD, Brown KS, et al. The syndrome of anosmia with hypogonadotropic hypogonadism: a genetic study of 18 new families and a review. Am J Med Genet 1983;15:417-435

6. Meitinger T, Heye B, Petit C, et al. Definitive localization of $\mathrm{X}$-linked Kallmann syndrome (hypogonadotropic hypogonadism and anosmia) to X.p22.3: close linkage to the hypervariable repeat sequence CRI-S232. Am J Hum Genet 1990;47 664-669

7. Baird PA, Robinson GC, Buckler WSJ. Klippel-Feil syndrome: a study of mirror movements detected by electromyography. Am J Dis Child 1967;113:546-551

8. Regli F, Filippo G, Wiesendanger M. Hereditary mirror movements. Arch Neurol 1967;16:620-623

9. Schott GD, Wyke MA. Congenital mirror movements. J Neurol Neurosurg Psychiacry 1981;44:586-599

10. Cohen LG, Meer J, Tarkka I, et al. Congenital mirror move ments. Abnormal organization of motor pathways in two patients. Brain 1991;114:381-403

I1. Danek A, Witt TN, Winter $T$, et al. Stimulation des motorischen Cortex bei hereditären Mirror-Movements. Z EEGEMG $1991 ; 21: 122$

12. Britton TC. Meyer B-U, Benecke R. Central motor pathways in patients with mirror movements. J Neurol Neurosurg Psychiatry $1991 ; 54: 505-510$
13. Konagaya Y, Mano Y, Konagaya M. Magnetic stimulation study in mirror movements. J Neurol 1990;237:107-109

14. Capaday C, Forget R, Fraser R, Lamarre Y. Evidence of a contri bution of the motor cortex to the long-latency stretch reflex of the human thumb. J Physiol [Lond] 1991;440:243-255

15. Farmer SF, Ingram DA, Stephens JA. Mirror movements in a patient with Klippel-Feil syndrome. J Physiol (Lond) 1990; 428:467-484

16. Claus D, Spitzer A. Zur Methodik der magnetischen Stimulation mit Doppelspulen. Z EEG-EMG 1991;22:24-27

17. Schwanzel-Fukuda M, Bick D, Pfaff DW. Luteinizing hormone-releasing hormone (LHRH)-expressing cells do not migrate normally in an inherited hypogonadal (Kallmann) syrdrome. Brain Res Mol Brain Res 1989;6:311-326

18. Salmaso D, Longoni AM. Problems in the assessment of hand preference. Cortex 1985;21:533-549

19. Fries W, Danek A, Witt TN. Motor responses after transcranial electrical stimulation of cerebral hemispheres with a degenerated pyramidal tract. Ann Neurol 1991;29:646-650

20. Witt TN, Garner CG, Oechsner M. Zentrale motorische Leitungszeit bei Multipler Sklerose: Ein Vergleich mit visuell und somatosensorisch evozierten Potentialen in Abhängigkeit vom Verlaufstyp. Z EEG-EMG 1988;19:247-254

21. Schwanzel-Fukuda $M$, Pfaff $D W$. The migration of luteinizing hormone-releasing hormone (L.HRH) neurons from the medial olfactory placode into the medial basal forebrain. Experientia 1990;46:956-962

22. Galaburda AM, Sherman GF, Rosen GD, et al. Developmental dyslexia: four consecutive patients with cortical anomalies. Ann Neurol 1985;18:222-233

23. Skene JHP. Axonal growth-associated proteins. Annu Rev Neurosci 1989;12:127-156

24. Lander AD. Understanding the molecules of neural cell contacts: emerging parterns of structure and function. Trends Neurosci $1989 ; 12: 189-195$

25. Conrad B, Kriebel J, Hetzel WW. Hereditary bimanual synkinesis combined with hypogonadotropic hypogonadism and anosmia in four brothers. J Neurol 1978;218:263-274

26. Forget R, Boghen D, Attig E, Lamarre $Y$. Electromyographic studies of congenital mirror movements. Neurology 1986;36: 1316-1322

27. Matthews PB, Farmer SF, Ingram DA. On the localization of the stretch reflex of intrinsic hand muscles in a patient with mirror movements. J Physiol (Lond) 1990;428:561-577

28. Aizawa $H$, Mushiake $H$, Inase $M$, Tanji J. An output zone of the monkey primary motor cortex specialized for bilateral hand movement. Exp Brain Res 1990;82:219-221

29. Nathan PW, Smith MC. Effects of two unilateral cordotomies on the motility of the lower limbs. Brain 1973;96:471-494

30. Benecke R, Meyer B-U, Freund H-J. Reorganization of descending motor pathways in patients after hemispherectomy and severe hemispheric lesions demonstrated by magneric brain stimulation. Exp Brain Res 1991;83:419-426

31. Nass R. Mirror movement asymmetries in congenital hemiparesis: the inhibition hypothesis revisited. Neurology 1985:35 1059-1062

32. Freiman IS, Micheels L, Kahn RL. A hereditary syndrome characterized by mirror-movements, left-handedness and organic mental defect. Trans Am Neurol Assoc 1949;74:224-226

33. Shibasaki H, Nagae K. Mirror movement: application of movement-related cortical potentials. Ann Neurol 1984;15: 299-302

34. Klingmüller $\mathrm{D}$, Dewes $\mathrm{W}$, Krahe $\mathrm{T}$, et al. Magnetic resonance imaging of the brain in patients with anosmia and hypothalamic hypogonadism (Kallmann's syndrome). ) Clin Endocrinol Metab $1987 ; 65: 581-584$ 